\title{
SIERPES DE CRISTAL CERVANTINO \\ EN LA FUENTE DE LA EDAD: \\ AUTORES Y TRUJAMANES \\ QUE ADMITEN RÉPLICA Y DISPUTA
}

RAFAEl Bonilla CEREzo

Universidad de Córdoba

Los esquemas narrativos de Luis Mateo Díez tienen su origen en el venero del que parte toda la novela moderna: el Quijote de Cervantes. Cuando se navega por Celama, las ondas remiten a una tradición "poética» que, lejos de ser herencia de signo individual, emergió con inusitado vigor en la oleada de escritores nacidos entre 1935 y 1950. Esta generación joven, todavía sin nombre (aunque se les haya aplicado los términos de "posmodernidad» y "realismo mágico»), se consolidaría en el triunvirato - José María Merino, Juan Pedro Aparicio y el propio Mateo Díez- que García de Nora cataloga como "nueva literatura leonesa» ${ }^{1}$. Todos bebieron de la oralidad y la leyenda, de la épica y el folklore, para reconocer su deuda con las huestes cervantinas ${ }^{2}$.

Semejante influjo opera de una forma muy singular, expuesta con brillantez en alguno de sus escritos sobre la fábula ${ }^{3}$. Aventuras nada grandiosas ni triunfadoras, de medio pelo, sedimentan

\footnotetext{
1 Eugenio García de NORA, «Notas para un encuadre de la narrativa leonesa actual», Ínsula, 572-573, Madrid, agosto-septiembre de 1994, pp. 11-12.

2 José MARía MERINo, en una de las intervenciones del «Encuentro de narradores leoneses», Ínsula, op. cit., pp. 3-7, afirma: «Es que es sorprendente que leas Huckleberry Finn y resulta que es hijo de El Quijote; leas Kim, de Kipling, y es don Quijote y Sancho Panza, etc. A estas alturas sería estúpido discutir a Cervantes; tan estúpido como me parece que se haga con Galdós, que es un noble abuelo que, si encima hubiera tenido estilo, hubiera sido el escritor más genial de la historia del mundo".

${ }^{3}$ ENRIQUe TURPIN en "La invención y la fábula en Luis Mateo Díez», Cuadernos de narrativa, núm. 4, Universidad de Neuchatel, 1999, pp. 91-105, ha trascrito estas palabras del autor: "Curiosamente mi primera experiencia con el Quijote [...] no es la de haberlo leído sino la de haberlo oído» (p. 96).
}

AC. XXXVI (2004), 309-328 
su producción ${ }^{4}$; empresas como las de Alonso Quijano, Lázaro y los restantes pícaros, que fascinaron desde muy temprano al futuro académico ${ }^{5}$. Peripecias en "tono menor» alumbrando una joya cristalina: La fuente de la edad ${ }^{6}$.

En esta novela, logrará multiplicar los recursos expresivos al servicio del humor caricaturesco. Sus protagonistas representan «auténticas máscaras, un paisaje humano descoyuntado que sirve de parodia de la existencia entre la alucinación y las situaciones que rayan en lo ridículo» ${ }^{7}$. La interpolación de episodios, el perspectivismo y los extraños individuos que pueblan el relato acaban por configurar un caudal mítico-festivo de raigambre áurea ${ }^{8}$.

El diseño ternario ( $\mathrm{El}$ baúl de don José María Lumajo» / «La ruta de la fuente» / "La flor de invierno») apunta las líneas de sentido que articulan la trama. En la primera parte, una cofradía profana - consagrada a los placeres de Baco- se propone encontrar el baúl de José María Lumajo: sus manuscritos velan el camino hacia la inmortalidad. El nocturno asedio a la casa número siete de la calle Pilares, dirigidos por Olegario el Lentes, y la consecución del ansiado tesoro ponen fin a los preparativos. La segunda gira en torno al Locus nemoroso, el viaje de los cofrades por la comarca de La Omañona en busca de la fons aeternitatis. En tercer lugar, y como colofón, la venganza que traman los burlados expedicionarios contra el «mundo provinciano» que los engañó ${ }^{\text {. }}$

${ }^{4}$ Santos Alonso estudia la filiación cervantina en su edición de LuIS MATEO DíEz, La fuente de la edad, Madrid, Cátedra, 2002, p. 20. A partir de ahora indicamos entre paréntesis junto al texto la página correspondiente.

${ }_{5}$ "Yo tuve la suerte de tener a mi lado muy pronto a don Alonso, de reconocerle con la aureola melancólica que irradiaba su triste figura. [...] De don Alonso aprendí que la imaginación puede suplantar a la realidad, que la locura es como un sueño que está más allá de la vida, que en ella se encierra la inocencia y a su lado acecha la muerte». Ibídem, p. 20.

${ }^{6}$ La novela se publicó en octubre de 1986 y obtuvo al año siguiente el Premio de la Crítica y el Premio Nacional de Literatura.

7 SANTOS Alonso, "La renovación del realismo», Insula, op. cit., pp. 12-14.

${ }^{8}$ MANUEL MORILla ha rastreado los hipotextos barrocos del itinerario tanto en su tesis doctoral como en "Esperpento y degradación en La fuente de la edad", Analecta Malacitana, XVIII, 2, 1995, pp. 447-457: el juego del viajero múltiple, el homo viator heredado del Persiles; el peregrino tratado en las Soledades gongorinas o en el Criticón; la fuente como "retorno al mundo maravilloso de la fantasía, manteniendo la figura del héroe [colectivo] una verosimilitud real y humana». Esta cita de Morilla procede de Antonio Vilanova, Erasmo y Cervantes, Barcelona, Lumen, 1989, p. 330. Queremos agradecer las facilidades ofrecidas por el investigador para consultar su magnífica memoria - todavía inédita- La novelística de Luis Mateo Diez: del viaje de la provincia a la perdición del camino. Máscaras, degradación y caricatura, pp. 77-84.

${ }^{9}$ Sintetizamos el argumento basándonos en las claves de lectura propuestas 
Se puede apreciar que la pesquisas en torno a los pergaminos - con un registro de estirpe valleinclanesca- y la ruta de la fuente reflejan las "sierpes clasicistas» que depuran su prosa. Sin embargo, la crítica no ha abordado los préstamos del «ingenioso hidalgo»; ya sea partiendo de la focalización autorial, el diálogo maravilloso o los homenajes - más o menos ocultos- a episodios del tapiz quijotesco. Estas cuestiones erigen el astillero sobre el que descansa el presente estudio.

Es sabido que El Quijote comienza como el cuento de un cuento, pues el autor admite que ha encontrado noticias de un tal Quijada en los anales de la Mancha $^{10}$. Sus ocho capítulos iniciales presentan un fecundo narrador - no especificado- que otorga carácter "histórico»"11 a aquello que comunica. De un artificio semejante se sirve Mateo Díez en La fuente de la edad, si bien introducirá ligeras variantes. Asumiendo la presencia del narrador omnisciente, reconocible a lo largo de todo el texto, delega en sus personajes la verosimilitud de los hechos ${ }^{12}$. En este sentido, la primera mención de don José María Lumajo está vinculada a Pacho Robla, militar que, como el cronista cervantino,

por ARCADIO LÓPEZ-CASANOVA en "Mito y simbolización en la novela (claves de una escritura generacional a través de tres relatos emblemáticos)», Ínsula, op. cit., pp. 15-19.

10 "Quieren decir que tenía el nombre de "Quijada», o "Quesada», que en esto hay alguna diferencia en los autores que de este caso escriben, aunque por conjeturas verisímiles se deja entender que se llamaba "Quijana» (I, 1). Cfr. MIGUEL DE CERVANTES, Don Quijote de la Mancha, Barcelona, Edición del Instituto Cervantes dirigida por Francisco Rico, Barcelona, Crítica, 1998, p. 37. En adelante citaremos por esta edición.

11 EDWARD C. RILEY, en "Tres versiones de la historia de Don Quijote», La rara invención. Estudios sobre Cervantes y su posterioridad literaria, Barcelona, Crítica, 2001, pp. 131-151, estima que el fragmento del primer autor no es tan fiable como en un principio pudiera parecer: "Se muestra vago con las fuentes, pero eso no importa. Lo que sí provoca que arqueemos las cejas es pillarle jugando con la información. Ya en la primera frase del libro oculta deliberadamente un dato esencial: 'En un lugar de la Mancha de cuyo nombre no quiero acordarme'...» (p. 136).

12 Como estudió BRUCE W. WARDROPPER en "Don Quijote: ¿ficción o historia?», El Quijote (coord. GEORGE HALEY), Madrid, Taurus, col. El escritor y la crítica, 1984 , pp. 237-252, «junto a la ficcionalización y falsificación de la historia se produjo un cambio fundamental en el papel del narrador. En la historia auténtica, el autor se retrae modestamente tras la narración. [...] La ficción, sin excluir el libro de aventuras que antecede a la novela, es más autoconsciente que la historia. [...] Cervantes, que en el Quijote está escribiendo la primera novela, complica enormemente el papel desempeñado por el autor» (p. 250). 
indaga en los archivos locales para elaborar la protohistoria de la comarca ${ }^{13}$ :

-De cualquier modo, no veo razones para pensar que alguno se haya ido de la lengua. Y la casualidad tampoco debe descartarse. Pacho Robla anda con lo de la protohistoria a cuestas, y no me digáis que por esos vericuetos no tiene que tocar la obra del ilustre presbítero. ¿Qué veis de raro en ello? (p. 99).

En principio, hemos de suponer que los datos extraídos por Robla son rigurosamente ciertos. Pero esta hipótesis queda difuminada por una réplica de Angel Benuza ${ }^{14}$.

-Uno lo que ve es al adusto coronel retirado - dijo Benuza - con la protohistórica chimenea de su cerebro echando un humo pestilente (p. 99).

- Necesitamos más información —concluyó Don Florín-. ¿De dónde procede esa correspondencia, quién la tiene? Imaginaros que el presbítero habla en ella del Manuscrito de La Omañona, que cuenta algo de la Fuente (p. 100).

Robla, un cerebro "protervo e insustancial», ha logrado acceder a los textos «histórico-imaginarios». En otras palabras, existe la posibilidad de que su futura reseña no utilice correctamente los pormenores apócrifos de Lumajo. Y esta omisión deriva en recelo -porque nadie acredita la autenticidad de las cartas más allá del

\footnotetext{
${ }^{13}$ A pesar de que Cide Hamete toma el relato en el capítulo nueve, conviene tener presente la importancia de estos anales para interpretar el Quijote y La fuente de la edad. En el caso cervantino se emplean para otorgar rigor a lo narrado, aunque ya hemos visto que esto es muy discutible. La novela de Mateo Díez acude a ellos como el punto de partida de don José María. De manera magistral quedarán subvertidos tras el artículo que escribe Robla hacia el final de la Segunda parte. El historiador juzgaba que ciertos datos descubiertos por Lumajo debían se negados. Para ello es necesario asumir que valoraba otros. Se burla de los cofrades por crear una imagen mítica del Presbítero siguiendo "sus fuentes» al pie de la letra, unos textos que resultarán ser apócrifos. Sin embargo, Robla carece igualmente de lucidez desde el instante en que utiliza para su protohistoria documentos del propio Lumajo.

${ }^{14}$ Luis Mateo Díez comienza a exponer esa polifonía de voces que Mikjail Bajtin establece como base de su exposición narrativa y que, según ÁNGEL BASANTA en Cervantes y la creación de la novela moderna, Madrid, Anaya, Biblioteca Básica de Lectura, 1992, fue diseñada por el alcalaíno tres siglos atrás: «El fértil juego de autores, traductores, narradores y lectores permite una extraordinaria libertad creadora, a la vez que siembra la ambigüedad y la duda en cada página» (p. 59). "La existencia de "dos autores» en la historia del caballero y la invención del manuscrito encontrado propicia el inagotable juego que da validez a cualquier perspectiva. Además intervienen múltiples personajes en continuos diálogos y cada uno lo hace desde su punto de vista individualizado por la lengua que emplea» (p. 64).
} 
propio coronel-, con lo que las directrices manuscritas «han sido vedadas» a lectores y peregrinos ${ }^{15}$.

Mientras la expedición parece condenada al fracaso, nuestros priostes esperan noticias de Aquilino:

-Yo confío que el martes o el miércoles Aquilino nos traiga alguna novedad -indicó Don Florín-. La entrevista en el Escorial con el padre Procopio, que tanto trabajo le ha costado concertar, puede ser importante (p. 104).

Este segundo «informador» tampoco resulta fidedigno pues, según precisa Benuza, tiene el juicio «empachado de escolásticas y teodiceas». No es más que un Alonso Quijano de la vida monástica:

-No nos hagamos ilusiones - dijo Benuza. Ese agustino tiene la inteligencia averiada y el resentimiento en la faltriquera. [...] ¿Leisteis su último libro? Conciencia y cruzada, la soflama moral de una urraca tiñosa y nacionalsindicalista (p. 104).

Ello no impide que la entrevista adquiera una especial relevancia. Conocemos que Robla se limita al ámbito de la letra impresa; esfera que no garantiza la verdad de los documentos porque Lumajo bien pudo inventarlos. El Padre Procopio no posee ningún texto escrito por el presbítero pero gozó de su compañía durante la época del fabuloso descubrimiento. Y si entre amigos surgen «medias verdades», los clérigos gozan con «mentiras piadosas». Por tanto, descartemos su punto de vista del reino de lo verificable. De la unión entre la fuente residual, que permanece en la memoria de Procopio, y los tomos históricos de Robla manaría algo de luz. Mateo Díez lo percibe y se cuida de ponerlos en contacto.

Convendrá contrastar nuestras intuiciones con Melendres, personaje ligado a la Peña de los Lisiados ${ }^{16}$. Este tabernáculo, «camino aquietado» e imagen de la célebre venta de Juan Palomeque ${ }^{17}$,

15 Javier Blasco utiliza estas palabras para demostrar que sólo el traductor morisco pudo tener acceso al texto del historiador arábigo. Cfr. «La compartida responsabilidad de la «escritura desatada del Quijote» (p. 56), Criticón, núm. 46, 1989, pp. 41-62.

16 «Hacia la Peña de los Lisiados, diezmada en el rincón del descansillo de donde se descuelgan las escaleras que bajan a la bodega, cruzaron los cofrades surcando las nieblas del Capudre, entre los amotinados jugadores y los impasibles clientes del porrón, esparcidos en los taburetes y en los escaños». La fuente de la edad, op. cit., pp. 110-111.

${ }_{17}$ A juicio de AMÉrico CASTRo, en "El cómo y el porqué de Cide Hamete», El pensamiento según Cervantes y otros estudios cervantinos, Madrid, Editorial Trotta, 
representa la sociedad donde la humanidad desfila. Un espacio - paralelo al lupanar de Emilia en la segunda parte- que cobija historias de viva $\operatorname{voz}^{18}$ :

«-Y tú, amigo Melendres, vas a contarnos alguna cosa porque, mira por donde, va a gustarnos mucho oírtela.

- Coño, coño, ya no sabe uno en lo que va a parar. Pero a vuestra disposición me tenéis, eso no hay que dudarlo» (p. 119).

El tercer filtro no está exento de problemas ya que don José María «habita» entre nublazones e incertidumbres. ¿Pertenecía a una comunidad parroquial? ¿Se convirtió en anacoreta? Los inconvenientes aumentan cuando recuerda que era un exégeta poco cartesiano y la desaparición de parte de su obra durante el incendio. Incluso en el caso de que los papeles guardados por Robla sean descifrables, la ilustración allí contenida no garantiza la solidez del escrutinio. Más aún, tal vez las pruebas que llevan a la Fuente perecieran en el fuego ${ }^{19}$. La vacilación es mayor cuando

2002, pp. 639-646, la Venta es ante todo «un observatorio para contemplar a quienes están yendo a alguna parte, y han emprendido el gran viaje del propio vivir, involucrado con otros ajenos al suyo. Las aventuras acontecen a quienes caminan y se topan con otros caminantes, en las rutas de la Mancha, o en el "camino aquietado" que es la venta. Se entenderá así mejor que Cervantes concibiera la factura de su audaz «empresa» literaria como un simultáneo movimiento de los autores y de... lo autorado por ellos" (p. 642).

${ }^{18}$ En la venta de Juan Palomeque Cervantes situará las burlas pseudopicarescas a don Quijote, el entremés de la pelea colectiva por el baciyelmo, la lectura de una novela en forma de manuscrito, la anagnórisis final de una comedia sentimental, otra de una novela de cautivos, etc. Según ha estudiado José MANUEL MARTÍN MORÁN, "escenas de diferentes géneros con un marco espacial único, con la característica común de ser un espacio acotado, ideal para la representación de sentimientos -o para la representación, simplemente-, que Cervantes utiliza para hilvanar todos esos géneros en la tela multicolor de su novela» (p. 302). Cfr. "La coherencia textual del Quijote», en La invención de la novela (estudios reunidos y presentados por JEAN CANNAVAGIO), Madrid, Colección de la Casa de Velázquez, vol. núm. 60, 1999, pp. 277-305. Leonardo Romero Tobar afirma que las secuencias en las que Mateo Díez se exhibe con mayor satisfacción son los fragmentos en que algún informante cuenta algo, bien su biografía, bien las costumbres locales, bien un romance o canción de la tradición oral. En este sentido, destaca la influencia, ya señalada por la crítica, de los filandones y los calechos. Para obtener una visión de conjunto del autor de $\mathrm{La}$ fuente de la edad, cfr. su artículo "La narrativa de Luis Mateo Díez», Estudios Humanísticos. Filología, núm. 7, 1985, pp. 9-20.

${ }_{19}$ "-No es sólo la obra de don José María lo que nos interesa, también su persona, todo lo que con él pueda relacionarse. Y desgraciadamente son muchas las lagunas a su alrededor. No hay proporción entre sus escritos y sus publicaciones. Era, según parece, un hombre desordenado, poco cuidadoso con sus cosas y para mayor desgracia, como sabrás, su casa de la Plaza Mayor se incendió y es muy difícil calcular los papeles de su archivo que allí se perdieron". La fuente de la edad, op. cit. p. 120. 
descubrimos que Melendres ni siquiera alternó con Lumajo. Participa de la fuente oral, si bien dicha aclaración procede más del comento popular que de la experiencia directa. Y todos sabemos la facilidad con que el pueblo suele deturpar la transmisión de un motivo; sobre todo cuando el argumento de auctoritas se apoya en una conversación de dos bebedores enajenados ${ }^{20}$ :

-Yo, la verdad - confesó Melendres-, del tal don José María poco sé. Algo que haya oído comentar (p. 120).

- Algo me dijiste - apuntó Jacinto Sariegos- de unas cartas de don José María, a las que se había referido Pacho Robla.

- Sí, de eso sí que me acuerdo, aunque mucha atención no presté porque estoy muy ajeno a esos temas. Pacho y Juanito, sobre todo, son los que más hablan de ello. Pacho está terminando la introducción del primer opúsculo de sus Estudios Protohistóricos Provinciales, y ahí, según parece, rebate muchas de las teorías de ese cura (p. 121).

No caigamos en el error de la credulidad. Melendres siguió la charla con escaso interés y ha confesado su fervor por el jugo vinícola, liturgia que suma un nuevo perjuicio a la declaración. Aceptar su plena consciencia implicaría asumir la fiabilidad del razonamiento. Pero enseguida anuncia que estos individuos no poseen todas las cartas del Presbítero: ¿carecen de la instrucción más decisiva? Dichas cartas, como en el caso de Cide Hamete y el traductor morisco ${ }^{21}$, son copias a máquina sobre un antiguo

${ }^{20}$ La narración de estos personajes puede encerrar un guiño al pórtico de $E l$ coloquio de los perros:

«-Pues de poco se maravilla vuesa merced, señor Peralta — dijo el Alférez-; que otros sucesos me quedan por decir que exceden a toda imaginación, pues van fuera de todos los términos de naturaleza: no quiera vuesa merced saber más sino que son de suerte que doy por bien empleadas todas mis desgracias, por haber sido parte de haberme puesto en hospital donde vi lo que ahora diré, que es lo que ahora ni nunca vuesa merced podrá creer, ni habrá persona en el mundo que lo crea $[\ldots . .$.

-Ya vuesa merced habrá visto - dijo el Alférez- dos perros que con dos lanternas andan de noche con los hermanos de la Capacha, alumbrándoles cuando piden limosna». Miguel DE CERvantes, Novelas ejemplares, vol. II, edición de Harry Sieber, Madrid, Cátedra, 1995, pp. 292-93.

${ }^{21}$ Se trata del primer homenaje a los múltiples narradores cervantinos, a la figura de Cide Hamete, al traductor morisco. Antes incluso de la aparición del Diario de la Omañona, Mateo Díez prefigura el juego de manuscrito e intérprete en las cartas del Presbítero. El esquema narrativo del Quijote es objeto de análisis detenido por parte de muchos críticos. Américo CASTRO, en «El cómo y el porqué de Cide Hamete», op. cit., p. 645, habla de varios autores iniciáticos que se reducen a uno al final del capítulo octavo (segundo autor). Este segundo autor halla al tercero en un cartapacio escrito en árabe por Cide Hamete Benengeli, cartapacio que será vertido al castellano por un morisco aljamiado. El morisco hizo algo más que traducir por lo que habría que hablar de un cuarto autor. 
papel de calco. Se encontraron en el archivo del cura, mutilado por el fuego -y quizá por el propio dueño-, un depósito que la sobrina de don José María organizó durante los últimos años de su vida. Habría que suponer la pericia de la muchacha como bibliotecaria, hecho éste más que discutible, y el progresivo deterioro que el tiempo fragua en la caligrafía de los ancianos ${ }^{22}$.

Antes de desaparecer, Melindres cede el testigo a un «segundo oidor», pues Olegario el Lentes tampoco trató con Lumajo. Si

GEORGE HALEY, en «El narrador en Don Quijote: el Retablo de Maese Pedro», El Quijote, op. cit., pp. 269-275, propone un "yo anónimo» que comienza la narración hasta el final del capítulo octavo. A éste le sigue un "segundo autor» que asume el «yo» y la narración con la descripción de su experiencia de lector insatisfecho con los ocho capítulos iniciales que le habían dejado en ascuas. Cervantes acude entonces al recurso del manuscrito de Cide Hamete hallado en Toledo y a la necesidad de un traductor. Queda un intermediario, el agente pasado por alto por aquellos que quieren identificar al segundo autor con Cervantes. El nebuloso personaje que cobra cuerpo al final del capítulo VIII, para hilvanar el fragmento del primer autor con el de segundo, y que reaparece en el capítulo final de la primera parte para hacer las últimas observaciones. RUTH EL SAFFAR, aceptando el esquema de Haley, ha profundizado en el más importante de los narradores ficticios: Cide Hamete. Cfr. "La unción del narrador ficticio en Don Quijote», El Quijote, op. cit., pp. 288-299. Según José Moreno Reguera, en El Quijote y la crítica contemporánea, Alcalá de Henares, Centro de Estudios Cervantinos, 1997, pp. 160-161, el esquema más claro - aspecto aún en cuarentena- es el diseñado por SANTIAGO FERNÁNDEZ Mosouera: 1) El autor de los primeros ocho capítulos; 2) Editor. Es el encargado de editar y hacer traducir las hazañas de Don Quijote; 3) El traductor; 4) Cide Hamete, el principal autor de la historia de don Quijote; 5) El autor definitivo, que controlaría toda la obra desde su comienzo y aparece en I, 8 y I, 52. Como podemos observar, se identificaría con el narrador omnisciente de La fuente de la edad que delega en sus personajes la responsabilidad de los hechos. Hemos decidido realizar este breve recorrido por el débito autorial quijotesco para mostrar la acumulación de filtros que Mateo Díez lleva a cabo en su novela, punto esencial de nuestro análisis.

22 "-¿Pero las habían visto, las tienen ellos?

-Pues sí, las tienen, por lo menos algunas. Son copias a máquina, de esas hechas con un papel calco azulón que puedes perder los ojos. Y provienen del archivo del cura.

-O sea, que tú las viste también.

-El otro día, en el Casino, Pacho nos enseñó una carpeta raquítica, descolorida, pero yo no me fijé mucho porque es un tema, ya os lo he dicho, que no me interesa. Eran unas copias de esas que no hay quien las lea. Las estuvieron viendo Juanito y él.

- ¿Y dijo que eran del archivo?

-Bueno, son de esas copias que deja el que las escribe. El cura, al parecer, en los últimos años vivió con una sobrina que le organizaba los papeles». La fuente de la edad, op. cit., pp. 121-22. Parece evidente que, aunque las escribiera a máquina el propio Lumajo, la atención habría disminuido durante la vejez. Por otra parte, no se indica cuándo fueron escritas a mano, pero es probable que fuera una labor bastante anterior. En tal caso, las investigaciones quizá siguieran otros derroteros, lo que unido a su falta de orden cuestiona la cronología y validez de unos documentos mal conservados. 
Cervantes multiplicó las voces por medio de distintos narradores, que a su vez eran lectores de aquél que les precedió, Mateo Díez complica la verdad de la fábula a través de «relatores orales», que - casi siempre- son «oidores» del anterior:

Bueno, Angelín - le dijo guiñándole el ojo y palmeándole la espalda-, voy a irme del pico algo más de la cuenta, y algo más voy a decirte de lo que antes preguntabas, ya que tanto interés tenéis en el asunto del cura. Las cartas las consiguió Pacho Robla donde Olegario el Lentes. Otra cosa ya no me preguntes (p. 124).

Cuando la búsqueda avanza por buen camino, Olegario se empeña en demostrarnos lo contrario. Nuestro perito conservó las cartas durante un tiempo y, lógicamente, estudió su mensaje. Sin embargo, le faltan los conocimientos históricos y geográficos que permitirían a Pacho Robla descubrir la Fuente. Por si fuera poco, ¡es un guía que apenas ve! ${ }^{23}$ ¿Llegarán junto a este cicerone al mirífico destino? Y, en tal caso, ¿quién puede asegurar la veracidad de los legajos? Incluso admitiendo que los documentos fueran los mecanografiados por Lumajo, ¿permanecieron intactos antes de desembarcar en Pacho Robla? ¿Son la huella de una peligrosa emendatio "olegariana»?

Tal vez el jeroglífico se reduzca a una historia que resiste con éxito la «teoría de la falsación». Nos movemos en el terreno de la novela, de la ficción verosímil. Toda su arquitectura de funambulista anhela preguntarnos - como Carlos Fuentes en su estudio sobre el Quijote ${ }^{24}$ - ¿quién ha escrito las legendarias epístolas? ¿Realmente existieron? Escuchemos al Lentes:

${ }^{23}$ ARCADIO LóPEZ-CASANOva, en "Mito y simbolización...», op. cit., p. 15, pone de relieve la visión mítica del episodio del baúl abandonado en la casa número siete (precisamente el siete) de la calle Pilares. "Trabajosa conquista que dirige Don Florín, en la que actúa de guía el susodicho Olegario, guía que apenas ve, en busca de un «tesoro ansiado que tiene celoso y fiero guardián («despierto dragón que transforma su cólera en fuego») bien certero en sus escopetazos contra Sariegos y Bodes, los dos cofrades que caen heridos».

${ }^{24}$ En el capítulo IX de su libro Cervantes o la crítica de la lectura, Alcalá de Henares, Biblioteca de Estudios Cervantinos, 1994, p. 97, Carlos Fuentes se pregunta: "¿Quién es el autor del Quijote? ¿Un tal Cervantes más versado en desdichas que en versos, cuya Galatea ha leído el cura que hace el escrutinio de los libros de don Quijote? ¿Un tal Saavedra, mencionado por el cautivo con admiración; en razón de los hechos que cumplió y todo por alcanzar la libertad? Cervantes, como Don Quijote, es leído por los personajes de la novela El Quijote, libro sin origen autoral y casi sin destino, agonizante apenas nace, reanimado por los papeles del historiador arábigo Cide Hamete, que son vertidos al castellano por un anónimo traductor morisco y que serán objeto de versión apócrifa de Avellaneda... Puntos suspensivos». 
Esas cartas aparecieron en una carpeta medio trabada en el cajón de un bargueño. Yo no reparé en ellas, A don Pacho le gustó el mueble y la verdad, es que me lo sacó por muy debajo de lo que yo pedía. Era un bargueño taraceado del mejor nogal, con unos herrajes superiores. Ya estaba hecho el trato cuando se puso a curiosear y salió la carpeta (p. 151).

El hallazgo de las cartas tiene lugar en una carpeta "medio trabada", es decir, semiabierta, y alguien ha cotejado las notas no hace mucho. Tal vez el «ingenuo» Olegario, quien afirma no haberles concedido demasiada importancia, reemplazara algunos pasajes por otros triviales. Una última duda se cierne sobre el arcón. ¿Quién fue su primer propietario? ¿De dónde procede ${ }^{25}$ ? Desconocido el dueño del piso donde se realizó la compraventa, el aviso llega a través de Emeterio, tercero de los «oidores» a los que antes aludíamos. Pero Olegario hizo el arriendo con Rosario, de la que ignoramos su origen e identidad. En ese instante, y de forma «casual», El Lentes se percata de la existencia de un receptáculo con documentos. La chispa que faltaba ha prendido en la imaginación de los cofrades. Sueñan con la "llave evangélica» de Lumajo: el misterioso baúl que permanece en la calle Pilares, celoso guardián de la revelación del maestro y depositario del saber virtuoso ${ }^{26}$. Pronto aprenderán que, como toda "odisea mítica», algunos pagarán con su sangre. No hay que preocuparse; existen bálsamos de Fierabrás, ungüentos fasgarinos a la vuelta de la esquina ${ }^{27}$ :

${ }^{25}$ «En el siete de la calle de Pilares, justo en la esquina de la Plaza Mayor - confesó exagerando su resignación-, en el segundo piso. Allí me vendieron el bargueño y una sillería. El piso debe de llevar deshabitado mucho tiempo. Ahora parece que lo compró uno que viene destinado al Catastro y que lo ocupará después del verano.

- ¿De quién es el piso?

-A mí me dio el aviso Emeterio el Lanas, me dijo que querían deshacerse de algunos trastos, mercancía buena y a no mal precio. Yo allí el trato lo hice con una paisana que se llama Rosario, no sé si es la dueña o quién, lo cierto es que ella manda y ordena.[...].

- ¿Documentos? [...].

—Un baúl - siguió Olegario, abundando en el recuerdo y en el pesar de darlo por perdido- lleno de papelorios, escritos, libros viejos. ¡Justo con lo que a don Pacho le hubiese sacado hasta la hijuela!». La fuente de la edad, op. cit., pp. 152-53.

${ }^{26}$ Según Ricardo SenABre, en «Temas y motivos en la narrativa de Luis Mateo Díez», Cuadernos de narrativa, op. cit., pp. 35-44, "viejos baúles, desvanes polvorientos, armarios abarrotados de utensilios heteróclitos, manuscritos en los que alguien quiso dar fe de su paso por la vida... Todos estos motivos -que tienen, no lo olvidemos, un origen biográfico- son imágenes, modulaciones de un tema único: la concepción de la vida como degradación, como ruina, como algo condenado irremisiblemente a la extinción y al olvido» (p. 37).

${ }^{27}$ Jacinto Sariegos y Paco Bodes son heridos en «las desnudas lomas» por el 
Todo eran libros. Volúmenes y volúmenes de pastas desconchadas y páginas invadidas por humedades y carcomas. Tratados teologales, diccionarios, florilegios, devocionarios, misales, guías de pecadores. Un enjambre de maltrechas piezas coleccionadas en una decrépita colmena. [...] Fue el grito final de don Florín lo que les hizo abalanzarse sobre el ya prácticamente vacío baúl, y descubrir allí, como el último resto de un extraviado patrimonio, un pequeño cuaderno, que una letra menuda signaba en la portada con el título de Diario de la Omañona, el nombre de don José María Lumajo, y una fecha difícil de apreciar de un septiembre de mil novecientos veintiocho (p. 198).

El tributo a la valija de Cardenio ${ }^{28}$ y, sobre todo, a la maletilla del ventero se desliza en la acción ${ }^{29}$. Esta colmena libresca coinci-

"cancerbero» de la calle Pilares. Cuentan sin embargo con el «ungüento fasgarino» elaborado en casa de Emilia: "Con el ungüento fasgarino y la pomada de lecherinas, dos de los productos más escrupulosamente logrados por don Florín, en las maniáticas investigaciones de su rebotica, preparó, sin poder disimular cierta avidez de inventor que se dispone a hacer la primera prueba, un emplasto de nata verdosa" (p. 191). Comparemos este pasaje con el capítulo 17 de la Primera parte del Quijote: "Hecho esto, quiso él mesmo hacer luego la experiencia de la virtud de aquel precioso bálsamo que él se imaginaba, y, así, se bebió, de lo que no pudo caber en la alcuza y quedaba en la olla donde se había cocido, casi media azumbre; y apenas lo acabó de beber, cuando comenzó a vomitar de manera que no le quedó nada en el estómago" (p. 181). La mención del bálsamo no es baladí, pues los lectores deben conocer que el cantar de gesta francés de Fierabrás expone que el rey sarraceno Balán y su hijo el gigante Fierabrás conquistaron Roma, la saquearon y robaron las sagradas reliquias allí veneradas; entre ellas dos barriles con restos del bálsamo con que fue embalsamado el cuerpo de Jesús, que tenía la virtud de curar las heridas de quien lo bebía. ¿No existen analogías más que evidentes con la Fuente de la inmortalidad, sin duda el gran desvelo de los cofrades, y el ungüento procedente de Fasgar, el pueblo del Caldero de Oro?

${ }_{28}$ «En esto alzó los ojos y vio que su amo estaba parado, procurando con la punta del lanzón alzar no sé qué bulto que estaba caído en el suelo, por lo cual se dio priesa a llegar a ayudarle si fuese menester, y cuando llegó fue a tiempo que alzaba con la punta del lanzón su cojín y una maleta asida a él, medio podridos, o podridos del todo, y deshechos; más pesaba tanto, que fue necesario que Sancho se apease a tomarlos, y mandóle su amo que viese lo que en la maleta venía»(I, 23). Miguel De Cervantes, Don Quijote, op. cit., p. 251.

${ }_{29}$ «Y entrando en su aposento, sacó dél una maletilla vieja cerrada con una cadenilla y, abriéndola, halló en ella tres libros grandes y unos papeles de muy buena letra, escritos a mano. El primer libro que abrió vio que era Don Cirongilio de Tracia, y el otro, de Felixmarte de Hircania, y el otro, la Historia del Gran Capitán Gonzalo Hernández de Córdoba, con la vida de Diego García de Paredes» (I, 32, p. 370) [...] «Llevábase la maleta y los libros el ventero, mas el cura le dijo:

-Esperad, que quiero ver qué papeles son esos que de tan buena letra están escritos.

Sacólos el huésped y, dándoselos a leer, vio hasta obra de ocho pliegos escritos de mano, y al principio tenían un título grande que decía Novela del Curioso impertinente (I, 32, p. 374). 
de con la «biblioteca» de Juan Palomeque en aspectos significativos: la mezcolanza de textos impresos y manuscritos, el interrogante que atañe al propietario que la abandonó y la presencia de un narrador destacado: Miguel de Cervantes, al parecer autor de las dos novelas allí encontradas, escritor de autógrafos y libros publicados, y José María Lumajo, «responsable» del Diario de la Omañona y de una obra arqueológica de gran éxito en la región. Las dos atribuciones son fruto de un pequeño recuento de ficciones e historias, viejas y nuevas, de las cuales, la última alcanza a revelar la identidad del prosista ${ }^{30}$. La diferencia estriba en que los libros del ventero no son fruto de una compra meditada; se trata de una «biblioteca ambulante» que ha caído en sus manos. La maleta de don José María contiene, por el contrario, obras que fueron utilizadas en sus investigaciones, si bien omite - frente a Quijano o Palomeque- los volúmenes de entretenimiento ${ }^{31}$.

Mateo Díez proporciona al lector la primera prueba escritural - «en primera persona»- de su huidizo clérigo. Recordemos, no obstante, que hasta el momento el único testimonio del Presbítero se limita a unas esquelas apógrafas. Las cartas - nunca lo olviden- eran unos duplicados trascritos, por lo que es ahora cuando irrumpen, en toda su pureza, las cabalísticas grafías de Lumajo. El problema incide en que ninguno de los cofrades - tampoco el resto de personajes - ha contemplado los trazos de este carnavalesco profeta. Por tanto, nadie puede dar fe de que el pequeño

${ }^{30}$ Riley subraya que los lectores que aprecien las asociaciones simbólicas tal vez disfruten con la idea de que las viejas ficciones e historias de caballerías aparezcan en el mismo saco que las creaciones de prosa más actual de Cervantes. Algo parecido sucede con el revoltijo de colectáneas y devocionarios que anteceden a la irrupción del Diario de la Omañona. Mucho más notable es la característica que singulariza en las dos novelas a este recipiente concreto: «su capacidad de actuar como vínculo transtextual. Enlaza con el medio interno de las ventas los venteros y los viajeros del marco exterior de referencia que contiene a Miguel de Cervantes. En el interior del texto, la maletilla se presenta como un objeto que posee la propiedad mágica de pasar de una dimensión a otra. En realidad, ése es un rasgo asombroso de la ficción: es capaz de adaptar incluso lo que viene de otra dimensión externa a sí misma» (p. 118). Cfr. EDWARD C. RileY, "Bultos, envoltorios y portamanteos. Un detalle de la técnica narrativa de Cervantes», $\mathrm{La}$ rara invención, op. cit., pp. 115-129.

${ }^{31}$ EDWARD BAKER ha puntualizado las diferencias que existen entre la biblioteca del ventero y la de los dos hidalgos manchegos, don Quijote y don Diego de Miranda: en el caso de estos últimos, sus libros proceden de su gusto por coleccionar aventuras de caballería. Entienden la lectura como actividad propia de un espacio doméstico que es la biblioteca. Los libros de Palomeque son tan ambulantes como lo es su maleta, tan transitorios como la propia venta. Es por ello que los estima como un breve hito en la vida de sus "desocupados lectores". Cfr. La biblioteca del Quijote, Madrid, Marcial Pons, Edic. Jurídicas y Sociales, 1997, pp. 143-148. 
cuaderno haya salido de su pluma. Sobre todo después de que la humedad y la carcoma se hubieran cebado con el cofre. Así pues, los compañeros de «lección» -todos los lectores- descubrimos que la datación del pergamino no es demasiado precisa. El laberinto de la incertidumbre tiende sus redes de nuevo.

Habrá que esperar a la segunda parte para obtener un aserto irrefutable. Don José María Lumajo compuso un tratado, la Tercera Excursión Arqueológica, muy célebre por los alrededores, que ofrece rasgos de empirismo en lo que respecta a la descripción física del manantial. El conflicto surge esta vez de nociones puramente literarias y cotextuales. Los estudios arqueológicos del Presbítero andan impresos y sin las galeradas no se puede ratificar la paternidad grafológica del dietario.

Desde la perspectiva estilística, los cofrades aprecian ciertas disparidades expresivas, un lenguaje críptico más conceptista que nunca. El Presbítero quiere decir y no dice, se ha convertido en un harúspice inspirado, en un sofisła que despliega un manto de ocultación sobre la escritura. El aliento de Cervantes circunda la descripción de esta prosa simbólica «que asciende en apacible ebullición pero no baja, ni surge de declive o ladera», como es propio de los afluentes quijotescos:

\footnotetext{
-Y eso es propio de los veneros que se filtran recoletos, en ensimismado fluir, como él dice. Parecida descripción hay en el Diario, aunque es evidente que el lenguaje del presbítero resulta más simbólico de lo que nos convendría. [...].

- Totalmente - confirmó Benuza-. El estilo del presbítero es, en el Diario, más tortuoso y sincopado que nunca.[...] Una suerte de velo turbio encubre la escritura, igual que en esas doloridas confesiones ológrafas de los convictos, que no acaban de resignarse a nombrar lo que hicieron ni el apellido de las víctimas (p. 208).
}

Ahora bien, renunciamos a problematizar las voces narrativas apoyándonos en refutaciones de las creencias. La genial vinculación de Mateo Díez con Cervantes radica en un episodio que adquiere una importancia definitiva: de forma paralela a las facecias, Benjamín Otero piensa trazar el «Diario de la expedición» a su amigo Julio Linaza. Una segunda vía novelesca a la que no accederemos, pues se desarrolla en la mente de Otero y descansa en las páginas de un cuaderno privado. Igual que Don Quijote, Benjamín inicia la redacción - simultánea al viaje y a lo narradode lo que, en su opinión, debería ser la ruta genesíaca:

Durante cerca de una hora describió Benjamín el viaje hasta la Omañona, el encuentro y los preparativos. No reparaba en ofrecerle a Julio todos los datos que amparaban la aventura, lo tomaba como cómplice interlocutor de lo que había sucedido y seguirá sucediendo, con 
esa directa confianza de quien ya adivina todos los secretos que uno conoce (p. 212).

Aunque el noticiero otorgue protagonismo a los sucesivos informantes del camino, la «autonarración ${ }^{32}$ de lo vivido - y escrito- sobrevuela la hazaña en todo momento. Desestimar el diario de Benjamín equivale a cercenar una de las claves de la obra: la visión poética de un peregrinaje en busca de la fe -muy distinta a lo propuesto por el autor primigenio- dentro de una novela que, curiosamente, narra la cruzada hacia la infinitud ${ }^{33}$.

Antes de proseguir su itinerario, cofrades y lectores disfrutan de la visión ofrecida por Rutilio y Basilio Candemuela. Con el primero medirán dos esferas bien definidas: oralidad / historia. Benuza ya «domina» todo lo necesario acerca de los escritos de Lumajo; ahora necesita enfrentar sus experiencias con la tradición popular:

-Don José María - dijo- fue la mayor inteligencia que diera esta comarca. Buena suerte tuve de conocerlo y tratarlo, y aprender de él lo que no pude en la escuela porque jamás tuve ocasión de pisarla. Ninguno de sus libros leí, pero mucho me acuerdo de cómo hablaba.

- Mis amigos conocen el asunto de la Fuente Virtuosa - le informó Aquilino- y es un tema que les interesa mucho.

- Para cualquier investigador, la injerencia del Mito en la roma realidad, es un aliciente - confesó Benuza. La idea de la Fons Aetatis siempre subyuga porque es una idea lírica y, en el fondo, quienes andamos por estos derroteros algo de poetas tenemos. Incluyo, cómo no, a don José María (pp. 220-221).

\footnotetext{
${ }^{32}$ Empleamos este término porque Benjamín redacta su Diario en primera persona con el objeto de enviárselo a su amigo Linaza, pero éste muere antes de recibir la ofrenda. Mateo Díez elimina entonces al receptor y potencial conocedor de la verdad de la expedición. Todo ello en el supuesto de que la historia de Benjamín sea sincera, lo que en principio, si atendemos a su "hermandad»con Julio, es más que factible.

${ }^{33}$ Esta segunda versión de los hechos entronca con aquella versión quijotesca, expresada en primera persona, en la que el hidalgo enuncia lo que cree que su encantador personal pondrá un día por escrito. Como ha indicado RILEY en «Tres versiones...», op. cit., p. 142, tal vez resulte sorprendente, pero hay un fragmento que pertenece claramente a esta obra: «Apenas había el rubicundo Apolo tendido por la faz de la ancha y espaciosa tierra las doradas hebras de sus hermosos cabellos...» (I, 2). Cfr. Miguel DE CERvanTes, Don Quijote, op. cit., p. 46. Al representar para nosotros estas fantasías de don Quijote, Cervantes se introduce en el ancho paisaje de la mente, por donde la imaginación se convierte en arte. Éste paisaje queda apuntado en el personaje de Benjamín, quien narra lo que ocurre en su imaginación o en su experiencia directa. La diferencia reside en que nuestra cultura descansa más en la influencia libresca, de ahí que lo recoja por escrito y no podamos leerlo, mientras que la de Quijano reposaba sobre la base de la oralidad.
} 
Mateo Díez funda en la oralidad la aproximación al hecho literario. Rutilio conoce la obra de Lumajo por vía directa ya que nunca leyó ninguno de sus ensayos. Esto nos lleva a dos conclusiones: 1) El pastor está privado de una formación mínima y no consigue exponer con nitidez las lecciones del «maestro»; 2) ¿Semeja un rústico de estirpe encinesca ${ }^{34}$ o, más bien, encarna al heredero del debate cervantino sobre la verosimilitud pastoril ${ }^{35}$ ? Los indicios apoyan esta segunda conjetura. Sin obviar su simpleza, las enseñanzas de Lumajo parecen haber moldeado el magín de Rutilio. De otro modo, sería imposible que comprendiera los engolados parlamentos de Benuza. Términos como «injerencia», "subyugar» o "derroteros» no son del todo ajenos a su entendimiento. La réplica del ovejero despejará nuestras incógnitas:

Fue en el verano de mil novecientos veintiocho - dijo- cuando ese hombre se echó a perder con sus quimeras.[...] Andaría por entonces por los setenta.[...] Andaba más enardecido que nunca, casi sin sosiego para apuntar las cosas y, más de una noche por el monte se quedaba. Un día le encontré en un campar no lejos de la Brañina del Garueño, adonde llevaba yo las ovejas. Estaba tumbado boca abajo junto a unas mantas, a la retestera del sol, y tan desnudo como su madre lo echó al mundo. Dormía. [...] Vi un hombre distinto, una persona a la que se le habían caído los años y estaba lozana tal como en la mocedad. [...] $\mathrm{Me}$ dio un frasco pequeño lleno de agua, y ya jamás hablamos nada del

34 «-¿Cuántos años lleva usted pastoreando por esos montes? [...]

-En el monte hay variedad como en la vida -afirmó-, aunque la del pastor sea toda una, y casi siempre la misma. De parideras, raboteos, esquilas, herraderos y enfardas está hecha, con las rastras y la impedimenta para arriba y para abajo». La fuente de la edad, op. cit., p. 218.

${ }^{35}$ El nombre del personaje lo vincula desde un primer momento a aquel Rutilio del Persiles, contador de «una historia que dejó a los oyentes admirados y contentos" (I, 8-9). Y no sólo coincide en el nombre sino en la peregrinación o la urdimbre de relatos de ficción que surgen de personajes "reales» ya descritos. Seguimos el texto de Miguel De Cervantes, Los trabajos de Persiles y Sigismunda, edición de JuAN Bautista Avalle-ArCe, Madrid, Castalia, 1992, pp. 88-98. Terminado el Discurso de la Edad de Oro, la narración del Quijote vuelve a enfocar a los cabreros, plano de la realidad cotidiana. Pero las elocuentes palabras de don Quijote han alertado nuestra imaginación y operamos, en opinión de Avalle-Arce, «dentro de un doble marco de referencias: el inmediato de los rústicos cabreros y el mediato y eludido del pastor real». Cfr. La novela pastoril española, Madrid Istmo, 1974, p. 249. Dicho discurso se puede relacionar con el problema de la ausencia de verosimilitud en el género, defecto que el propio Cervantes le achaca en El coloquio de los perros, op. cit., p. 307: "consideraba que no debía de ser verdad lo que había oído contar de la vida de los pastores, a lo menos, de aquellos que la dama de mi amo leía en unos libros cuando yo iba a su casa». Pasaje que debe ser relacionado con un clarificador fragmento sobre el tema inserto en el mismo Quijote (I, 25, p. 285): «¿Piensas tú que las Amarilis, las Filis, las Silvias [...] fueron verdaderamente damas de carne y hueso?». 
asunto ni preguntarle quise. Antes de acostarme vacié el frasco en mis pies, y mano de Santo. Nunca más, y ustedes me perdonen, me cantaron, yo que tenía la desgracia de que hasta los corderos me huyeran (pp. 222-223)

Esta analepsis bosqueja a grandes rasgos la fisonomía de Lumajo. Su eikonismós enfoca a un personaje quijotesco, inserto en su mundo de utopías. Los cómplices, que ya estamos sobre aviso, cuestionaremos la descripción de Rutilio. En principio, no deja de ser un hombre consagrado al pastoreo, condición que, más allá de sus incipientes progresos, lo prefigura como asilvestrado. Por encima de este rasgo, y suscribiendo la propiedad de su discurso, no tarda en revelar que el Presbítero vive a mitad de camino entre la furia ariostesca de Cardenio y la idealización de Don Quijote $^{36}$. ¿Nos someteremos al milagro paródico que obró sobre sus pies? ¿Es la burla de un loco montaraz hacia un «discípulo» iletrado?

La inseguridad para clarificar estos dilemas exige la presencia de un nuevo relator que con anterioridad - como Rutilio- fue oyente. Basilio Candemuela guarda una evidente similitud con el rústico: la procedencia local de los datos relativos a Lumajo. Sólo admite una objeción: Rutilio obtuvo esa confidencia del propio Presbítero mientras que la información de Candemuela nace de terceros. Aunque lo conoció de joven, todo lo que intuye sobre él se lo escuchó contar a su padre o a los lugareños. Por este motivo, acude a Aquilino para que ratifique su opinión sobre el «viejo sabio»:

-Lo que les digo, y tú, Aquilino, más de una vez lo habrás oído, es que el tal presbítero, entre otras muchas cosas que de él se dicen, salió

${ }^{36}$ Cardenio, avergonzado por la incapacidad para defender a su esposa, huye a la sierra donde pierde la identidad tras reiterados accesos de enajenación. Todos recuerdan que cuando don Quijote lo ve por primera vez aparece vestido de harapos. El cabello y la barba intonsos revelan los meses pasados en aquella vida salvaje, y una agilidad de cabra montés indica su completa adaptación al nuevo medio. Como estudia STEPHEN GILMAN en «Los inquisidores literarios de Cervantes», El Quijote, op. cit., pp. 122-141, "si Dorotea ha cambiado de papeles y de ropa, éste ha abandonado su anterior categoría social para vivir sin ninguna, como una bestia» (p. 132). El personaje de don José María no culmina semejante animalización pero se despoja de su vida anterior para saltar por los montes. Contrastemos la aparición en escena del Presbítero con la de Cardenio: «Yendo, pues con este pensamiento, vio que por cima de una montañuela que delante de los ojos se le ofrecía iba saltando un hombre de risco en risco y de mata en mata con estraña ligereza. Figurósele que iba desnudo, la barba negra y espesa, los cabellos muchos y rabultados, los pies descalzos y las piernas sin cosa alguna; los muslos cubrían unos calzones al parecer de terciopelo leonado, más tan hechos pedazos, que por muchas partes se le descubrían las carnes» (I, 23). Cfr. Miguel DE CERVANTES, Don Quijote... op. cit., p. 255. 
una vez con el cuento de que había encontrado una Fuente virtuosa y, coño, allá de setentón tiró de sotana y, según los rumores, empezó a hacer vida de mozo calavera. [...].

- Lo de la Fuente, como tantas otras hazañas, no fueron habladurías, Aquilino - aseguró-. No es que yo tratara mucho a aquel hombre, pero mi padre y mi tío Alipio sí. Con don Cosme el notario y don Severino el de la serrería, armaban unas timbas de campeonato. [...].

- La tal Fuente en ninguno de sus escritos la menciona, al menos de forma directa - dijo Ángel Benuza (pp. 256-57).

Comienza a vislumbrarse la fabulación que afecta a la Fons Aeternitatis y su destino en la novela. Los cofrades requerían un grial, un arca de la alianza que dé sentido al mundo de fantasía que han construido. En la opresora España de los años cincuenta, este grupo de soñadores postula un entorno dominado por el profeta y la fuente de aguas salvadoras. Tanto uno como otra carecen de entidad para el resto de los habitantes; entre las gentes, Lumajo no es sino un cura perturbado que elaboró una historia descabellada. Pero los cofrades necesitan creer, necesitan entronizar a su particular patriarca para que su aventura tenga sentido. Sin Diario no hay peripecia; sin Lumajo no hay Diario ${ }^{37}$.

El clan tabernario fabrica una imagen mesiánica que dota de trascendencia a su camino. Igual que gestaron a Orestes Enebro $^{38}$, igual que Don Quijote ideó un historiador para dar cuenta de sus hazañas ${ }^{39}$, han descubierto un modelo para opi-

${ }^{37}$ De esta manera, don José María ocupa en la novela una posición peculiar, parecida a la de Cide Hamete en el Quijote. Se halla en una situación periférica respecto a la leyenda que pasa a ser central en el libro y aventuras de los cofrades. Se mantiene a corta distancia del narrador omnisciente y la narración, y a menos espacio todavía entre la narración y el lector. Cfr. EDWARD C. RILEY, Teoría de la novela en Cervantes, Madrid, Taurus, 1981, p. 319.

${ }^{38}$ Partiendo de la realidad, los cofrades crean una imagen de Lumajo que no es tal. Previamente aplican este magistral ejemplo de perspectivismo vital y literario a la figura de Orestes Enebro: «Orestes Enebro fue el nombre que le dimos a aquel personaje que aquí se sentaba con nosotros todos los días, a quien guardábamos su sitio y le servíamos su plato y su vaso. Tenía Orestes mis tres dedos, el brazo de Avelino, la pierna de Pelines, el ojo de Feito, la nariz de Eloy y, dentro del mayor secreto, los huevos de Toribio, aquellos de los que el pobre estaba privado sin la más mínima posibilidad de resignación». La fuente de la edad, op. cit., p. 115.

${ }^{39}$ Cide Hamete tiene - como don José María - un peculiar origen funcional dentro de la propia novela. En el paso de una parte a otra de la versión histórica, según señala RILEY en "Tres versiones...», op. cit., p. 134, «el segundo autor hace notar la imposibilidad de que un caballero andante como Don Quijote no tenga un biógrafo personal (I, 9). Y de hecho, desde el principio, el protagonista cuenta con ello. Cuando sale a buscar aventuras por primera vez, en el capítulo 2 , supone claramente que el cronista encantador existe: "Quién duda sino que en los venideros tiempos, cuando salga a luz la verdadera historia de mis famosos 
nar, un «entreverado loco» que escapó de la realidad que lo oprimía ${ }^{40}$.

La nota distintiva de Basilio incide en su papel "positivista»: es el único personaje presente en el salutífero manantial. Perdido durante la conversación con el oráculo, fue testigo directo del riachuelo. Pero este "prodigio" queda muy lejos de su memoria y no perpetúa ninguna revelación especial. El efecto del agua sólo se producía en los elegidos, en aquellos que admiraban - ciegamente- su enorme poder. Y todo ello asumiendo una nueva hipótesis todavía por dilucidar: don José María no acompañó a esta familia en la cañada. Al fin y al cabo, la versión definitiva de aquel exemplum sobre un rey que, completamente desnudo, se muestra convencido de sus esplendorosos ropajes:

-Fuimos a la Fuente - dijo-, coño que si fuimos. [...] El efecto del agua se producía misteriosamente, no se trataba de un puro milagro, así lo advirtió. Como en esos cuentos de hadas en que unos visten y ven lo que otros no pueden, porque, según parece, estas cosas funcionan de modo caprichoso. Vamos, que no hay mayor capricho que el de la consabida quimera en que uno se empecina (p. 258).

Pronto escucharán nuestros cuentacuentos la voz de un niño que exclama « $i V a$ desnudo! ¡El monarca ha perdido su ropa!». En este caso, el choque de bruces con la realidad se precipita en un artículo leído por Ovidio ${ }^{41}$. Lo firma Mucio Petavonio, seudónimo de Pacho Robla:

hechos», Miguel de Cervantes, Don Quijote..., op. cit., p. 46. Así, hay un argumento a favor de la idea de que Cide Hamete nace en la novela porque Don Quijote lo necesita. Y es que un relato fundamentalmente histórico - como el de las aventuras del hidalgo - precisaba, obviamente, un biógrafo que en este caso es creado por el protagonista. Si trasladamos este axioma a La fuente de la edad, se puede apreciar que - si bien don José María existió- la figura del Presbítero ha sido elaborada por sus devotos cofrades. En ningún momento escuchamos a Lumajo y ello se debe, por encima de cualquier otra circunstancia, a que la visión que de él tienen los expedicionarios es la que han construido para racionalizar la ruta.

${ }^{40}$ Los priostes fabrican su propio perturbado sin saberlo. Sin embargo, cuando deciden vengarse de los demás habitantes (cambiando las bebidas del certamen literario) dan muestras de una cordura evidente. En este sentido también coinciden con Don Quijote, quien actúa como un loco en lo concerniente a la caballería andante y razona con sano juicio en otras cuestiones. Así lo entendieron Arturo Serrano Plaja y Gonzalo Torrente Ballester cuando explican la demencia de don Quijote como un juego codificado en la ficción que el caballero respeta siempre. Cfr. Gonzalo Torrente Ballester, El "Quijote» como juego, Madrid, Guadarrama, 1975.

${ }^{41}$ La fuente de la edad concuerda con el Quijote en la publicación impresa de las propias aventuras. Pese a todo, se distancian en un aspecto que nos parece esencial. En el primer caso, todos los personajes implicados acceden a la lectura 
- "Galopines pasados por agua» se titula. Dice que con un simple cebo metido en un baúl se puede conseguir que piquen los bobos que se las dan de listos, los fatuos que se tragan las historias más descabelladas. Sobre todo cuando esos bobos son visionarios de medio pelo. [...].

-Galopines pasados por agua -leyó, con visible preocupación-. Andan estos días por los equívocos caminos de nuestra bella comarca de La Omañona, unos desvariados galopines que igual se las dan de estudiosos que de plumíferos, no pasando nunca de beoda pandilla a la que es más habitual ver en el chigre que en la biblioteca (pp. 314-315).

Todo era una falacia, el mundo de ensueño se ha derruido bajo sus pies. Arrastrado por la corriente del escarnio, no hay ya fuente ni profetas que permitan atravesar el espejo. Sólo les queda un consuelo que simboliza el mayor de los triunfos. La historia de su aventura corre impresa, como circulaba la Primera parte del Quijote. Se han transmutado en seres literarios ${ }^{42}$. Abandonan su ca-

del artículo de Robla. El Quijote, en cambio, ofrece la información a través de Sansón Carrasco en el capítulo segundo de la Segunda parte. Poco después, el Caballero del Verde Gabán acaba de conocer a Don Quijote, y aún le dura la sorpresa del encuentro, cuando expresa su opinión acerca de la historia que el estrafalario caminante le ha dicho que anda impresa con sus "hazañas»: "—iBendito sea el cielo!, que con esa historia, que vuesa merced dice que está impresa, de sus altas y verdaderas caballerías se habrán puesto en olvido las innumerables de los fingidos caballeros andantes, de que estaba lleno el mundo, tan en daño de las buenas costumbres y tan en perjuicio y descrédito de las buenas historias» (II, 16, pág. 753). Como demostró Martín Morán, «el Verde, que no había leído el Quijote de 1605, no podía saber que ésa era la pretensión primordial del libro, ni Don Quijote se lo había podido dar a entender; a quien en realidad escuchamos, de nuevo, es a Cervantes mientras le recuerda al lector la semilla en que se puede contener toda la primera parte». Cfr. José MANUEL MARTín MORÁN, op. cit., pp. 291-292. En consecuencia, se puede afirmar que, al menos durante un breve espacio de tiempo (el preciso para leer la novela), el Caballero no podía conocerla lo que obligó a Cervantes a irrumpir en el texto. Mateo Díez delega desde el primer instante toda la responsabilidad en personajes, oidores y lectores por lo que no intervendrá en ningún momento, ni siquiera a través de un narrador omnisciente. Todos los personajes leen lo que se escribe sobre ellos y todos podrán emitir su juicio.

${ }^{42}$ Al principio de la Segunda parte, Cervantes conquista uno de los fuertes más geniales de la literatura. La noticia se la da Sansón Carrasco, el graduado de Salamanca: se ha publicado un libro sobre ellos en el que un tal Cide Hamete Benengeli cuenta sus primeras aventuras y ahora son famosos en todas partes: "yéndole yo a dar la bienvenida me dijo que andaba ya en libros la historia de vuestra merced, con el nombre de Ingenioso Hidalgo don Quijote de la Mancha, y dice que me mientan a mí en ella con mi mesmo nombre de Sancho Panza, y a la señora Dulcinea del Toboso, con otras cosas que pasamos nosotros a solas, que me hice cruces de espantado cómo las pudo saber el historiador que las escribió» (II, 2). Cfr. Miguel De CervanTes, Don Quijote..., op. cit., p. 645. Es evidente que la historia de los cofrades no la conoce todo el mundo, pero ya dijimos que se trataba de una peripecia de "tono menor». Lógicamente, todos los lugareños están informados sobre el devenir de los personajes a través de la prensa. No es ésta la narración épica de Don Quijote sino que, respetando escrupulosamente el 
reta de «discípulos» presbiteriales para convertirse en actores de sus propias aventuras ${ }^{43}$.

Cierto es que, ante los ojos de sus convecinos, serán objeto de burla; pero tanta certeza existe en la diatriba esperpéntica de Robla como en el desconocido Diario de Benjamín. Una y otro son complementarios. La postura en favor de un universo metarreal se enfrenta a un pliego que hunde sus raíces en la rutina y la envidia. Una gacetilla, no lo olvidemos, maquinada por el primero que manejó la obra de don José María. Parece, por tanto, que no hay milagro posible para las «extraviadas» almas que, tan fácilmente, van embaucadas en su torpe locura, sin distinguir lo falso de lo verdadero, la razón de la quimera. Queridos lectores, el engañador ha sido engañado.

\footnotetext{
decorum, los humiles protagonistas son conocidos por medio de una difusión igualmente humile. Ahora bien, esta incursión en la novela de la publicación real de la primera parte - en el primer caso- o de las aventuras milagreras - en el segundo- posee un efecto igualmente perturbador para los lectores. Involucrados de manera definitiva, se encuentran en la misma situación que los propios «peregrinos». De éste modo, los cofrades reaccionan y, en lugar de insistir en su empeño, deciden vengarse de aquellos que los burlaron. Esto denota una clara conciencia de los hechos y un considerable alejamiento del plano de la locura. Es entonces cuando el lector debe interpretar si realmente son unos individuos tan trastornados como parecía. Habrá que recurrir de nuevo a las palabras de Cervantes relativas a la Cueva de Montesinos (II, 24): «Tú letor, pues eres prudente, juzga lo que te pareciere». Cfr. Miguel DE Cervantes, Don Quijote..., op. cit., p. 829.

${ }_{43}$ Como le sucedía a Don Quijote, el hecho de saberse leídos es crucial para determinar los sucesivos niveles de lectura. Si en opinión de CARLOS FuENTES, op. cit., p. 79, «Don Quijote deja de apoyarse en la épica para empezar a apoyarse en su propia epopeya», los cofrades dejan de apoyarse en la mística para empezar a apoyarse en su venganza.
} 